\title{
Indications for Caesarean Sections in Rundu State Hospital in Kavango East Region, Namibia
}

\author{
Saara Kerthu Hatupopi ${ }^{1}$, Mirjam Nghamukamo ${ }^{1}$, Emma Maano Nghitanwa ${ }^{2} \&$ Olivia Ningeninawa Tuhadeleni $^{3}$ \\ ${ }^{1}$ Department of Midwifery Science, School of Nursing, Faculty of Health Sciences, University of Namibia \\ (UNAM), Rundu campus, Namibia \\ ${ }^{2}$ Department of Midwifery Science, School of Nursing, Faculty of Health Sciences, University of Namibia \\ (UNAM), Main campus Windhoek, Namibia \\ ${ }^{3}$ Department of Community Health Nursing Science, School of Nursing, Faculty of Health Sciences, University \\ of Namibia (UNAM), Rundu campus, Namibia \\ Correspondence: Saara Kerthu Hatupopi, School of Nursing, Faculty of Health Sciences, University of Namibia \\ (UNAM), PO Box 88, Kaisosi Road, Rundu, Namibia. E-mail: shatupopi@unam.na
}

Received: July 15, 2019 Accepted: September 9, 2019 Online Published: September 17, 2019

doi:10.5539/gjhs.v11n11p120 URL: https://doi.org/10.5539/gjhs.v11n11p120

\begin{abstract}
Background: A caesarean section is a life saving procedure for both the mother and the baby. However, the fact that caesarean section rates are increasing worldwide, in both the developed and developing countries is becoming an issue of increasing concern, which raised a concern. The purpose of this study was to evaluate the indications for a caesarean section in the Rundu State Hospital.
\end{abstract}

Methods: A cross sectional retrospective study was conducted.The study population comprised the records of women who had undergone caesarean section between 1 January 2017 to 31 March 2017. After conducting a sample size calculation the delivery, records of 149 women who had undergone a caesarean section during the study period were reviewed. The required data was collected using individual data collection sheets and then analysed using SPSS version 24.

Results: The age of participants ranged between 20 and 50 years. The mean age for the study group was 25.1 years. The overall leading indications for a caesarean section included foetal distress $(25.6 \%)$, previous uterine scar $(18.1 \%)$ and Cephalopelvic disproportion $(16.1 \%)$ while other major contributing indications were eclampsia (16.1\%), mal-presentation (8.1\%), prolonged labour (6.7\%, ante partum haemorrhage (3.4\%), failed vaginal birth after caesarean section $(2.0 \%)$, cord prolapse $(1.3 \%)$ and severe vaginal warts $(0.6 \%)$. In addition, the study found that a primary caesarean section was more common at $81.9 \%$ as compared to previous uterine scar at $18.1 \%$ while maternal indications contributed to $61 \%$ of caesarean sections while foetal indications constituted $39 \%$.

Conclusion: Overall, the study found that the leading indications for caesarean section were foetal distress and previous uterine scar. It was recommended that foetal distress, as the main indicator for a primary caesarean section, should be further confirmed with a printed cardiotocograph. Training health workers on the interpretation of cardiotocograph and the importance of the use of other methods, such as the fetoscope and doptone, may help to reduce the incidence of unnecessary primary caesarean section due to foetal distress. In addition, previous uterine scar cases should be embark on labour before a decision is made.

Keywords: caesarean section, indication, pregnancy, previous caesarean, primary caesarean section

\section{Background}

The term caesarean section $(\mathrm{C} / \mathrm{S})$ refers to the delivery of a foetus, placenta and membranes through an abdominal and uterine incision after 28 weeks of gestation (Moges et al., 2015). A C/S is carried out in obstetric emergencies where immediate action is vital to prevent the deaths of the mother, unborn foetus or both and is usually carried out in incidences in which a vaginal delivery could endanger the health and/or the lives of foetus and / or mother (Makori, 2015).

Globally, the rate of $\mathrm{C} / \mathrm{S}$ has been increasing significantly. The rate of $\mathrm{C} / \mathrm{S}$ varies from continent to continent with Asia at $46 \%$ followed by both, Europe and Latin America at 33\% respectively and Sub-Saharan Africa at $6.2 \%$ 
(Patah\& Malik, 2011). However, despite the increase in the rate of $\mathrm{C} / \mathrm{S}$ has presented a general increasing trend, thus leading to an upsurge in health service costs and the risk of maternal and perinatal morbidity and mortality, there has been no impact on decreasing the maternal and perinatal mortality rates (Molina et al., 2015).

Nevertheless, the need for a $\mathrm{C} / \mathrm{S}$ may play a vital role in providing the care for every pregnant woman. On the other hand, every $\mathrm{C} / \mathrm{S}$ leads to an increase in the $\mathrm{C} / \mathrm{S}$ rate and is accompanied by possible complications (Betran et al., 2007). In addition, women who undergo a $C / S$ are likely to have a repeat $C / S$ in a subsequent pregnancy, thus increasing the $\mathrm{C} / \mathrm{S}$ rate in a country with poor resources (Betrán et al., 2007). Moreover, there is ample evidence in the existing literature that there is increased maternal and neonatal morbidity and mortality associated with caesarean deliveries worldwide when compared to a normal vaginal delivery (NVD) (Kirchengast \& Hartmann, 2019). In addition, infection, haemorrhage, complication arising from the anaesthesia, bladder damage, prolonged hospitalisation and delayed recovery are common complications associated with a C/S (Pallasmaa et al., 2010). A recent study identified that the risks of placenta praevia, morbidly adherent placenta and obstetric haemorrhage in subsequent pregnancies also increase in the case of repeated C/S (Xu et al., 2019).

The factors influencing a $\mathrm{C} / \mathrm{S}$ are interrelated, complex, and may differ from one continent to another. Researchers have identified various factors that results in women undergoing a C/S. Barber et al.(2011) conducted a study in the United States of America (USA) which identified factors such as the arrest of dilatation and non-reassuring foetal monitoring heart tracings as playing a significant role in the increasing $\mathrm{C} / \mathrm{S}$ rates. Furthermore, the study also documented that medical indications, such as maternal, foetal or obstetric conditions contribute to the increasing rate of C/S (Barber et al., 2011). A study conducted by Abebe et al. (2016) on factors leading to C/S delivery at the Felegehiwot referral hospital in northwest Ethiopia identified that obstructed labour (30.7\%) foetal distress $(15.9 \%)$ and abnormal presentation (13.4\%) were the major obstetric indications of a C/S. In addition, the study also identified other factors as maternal age and parity, failure to progress in labour and non-obstetric factors such as maternal request as playing a role in the $\mathrm{C} / \mathrm{S}$ rate (Barber et al., 2011).

In Namibia, the C/S rate between 2005 and 2010 was 13\% according to global statistics report, (WHO 2012). During that period, Namibia was still in the acceptable right range (10-15\%) as per the WHO guidelines (WHO, 2009). However, a study conducted by Shikwambi (2014) in the Khomas region in Namibia identified that the C/S rate had increased to $23.9 \%$ while the proportion of non-elective $\mathrm{C} / \mathrm{S}$ was $72.2 \%$. Shikwambi (2014) further highlighted that the main cause of $\mathrm{C} / \mathrm{S}$ among low risk women were the poor assessment of maternal wellbeing and the progress of labour (Shikwambi, 2014). Rundu State Hospital reported $242 \mathrm{C} / \mathrm{S}$ cases between 1 January and 31 March 2017. The high numbers of $\mathrm{C} / \mathrm{S}$ is a matter of concern as it results in high healthcare costs, increased workload and challenges in ensuring improved quality of care when compared to NVD, which is natural way of delivery and linked to both rapid recovery, a relatively short hospital stay and maternal satisfaction (Kirchengast\& Hartmann, 2019). Rundu hospital serves as a referral hospital in the Kavango east and Kavango west constituencies with a total catchment population of 63431 (Namibia Statistics Agency, 2011). It is usually women with high-risk pregnancies who are referred to this hospital. However, women from the nearest constituencies also deliver at this hospital without being referred as it also serves as the district hospital. At the time of the study, there was no evidence of research having been conducted at the Rundu State Hospital to identify the indications leading to the high rate of $\mathrm{C} / \mathrm{S}$. It is, thus, recommended that efforts should be made to both improve access to and reduce the use of $\mathrm{C} / \mathrm{S}$ (Molina et al 2015). In the developed countries, $\mathrm{C} / \mathrm{S}$ rates have increased and attention is being focused on interventions to decrease its use (Betran et al., 2007). It is, therefore, imperative that an evaluation is conducted of the indications of $\mathrm{C} / \mathrm{S}$ in Rundu State Hospital as the findings of such an evaluation may inform ways to safely reduce the incidence $\mathrm{C} / \mathrm{S}$ in the population under study and improve the quality and efficiency of the care provided.

\section{Methodology}

The study was conducted in the Rundu Intermediate Hospital. According to the Rundu Hospital statistic, there were $242 \mathrm{C} / \mathrm{S}$ deliveries conducted between1 January 2017 to 31 March 2017. The study used a cross sectional, retrospective study design. Simple random sampling was used to select the documents required while Yamane's (1967) formula for sample selection was used to calculate the sample as follows:

$\mathrm{n}=\frac{N}{1+N x \alpha^{2}}$ Whereby the sample size; $\mathrm{N}$ is the population size under study and $\boldsymbol{\alpha}$ is the level of significance, which was 0.05 . Thus, the formula $n=\frac{242}{1+\left(242 \times 0.05^{2}\right)}=150$ was used to determine the sample size, however only 149 clinical records of women who had undergone a $\mathrm{C} / \mathrm{S}$ after the period of viability, namely, 28 weeks, within a given time were accessed and reviewed. The documents were reviewed to determine the indications of the $\mathrm{C} / \mathrm{S}$ they had undergone using a predesigned questionnaire. The data retrieved from the files, including age, gravida; primary 
and repeat cases were used in the study. The Statistical Package for Social Science (SPSS) version 24 was used to analyse the data while descriptive statistics were used to describe the data.

\subsection{Research Ethics}

Permission to conduct the study was obtained from the Ministry of Health and Social Services and from the Rundu Hospital management team. The study did not reveal any personal data, for example, names, pertaining to the women those files were reviewed. In other words, their anonymity was respected. In addition, the anonymity and the confidentiality of the information collected was ensured through the use of codes. All the files relevant to the research topic and kept by the hospital had an equal chance of being selected.

\section{Results}

\subsection{Demographic Profile of Women}

The ages of the participants were ranged between 20 and 50 years with the majority of the participants $(n=68)$, namely, $45.63 \%$, being in the age group 20 to 30 years, followed by $(n=40)$, namely, $26.84 \%$, being in the age group 13 to 19 years, while $14.76 \%(n=22)$ were aged between 35 and 49 years while one participant was 50 years old. The results are presented in table 1.The mean age for the study group was 25.1 years.

\subsection{Age}

Table 1. Age of participants

\begin{tabular}{lcc}
\hline Age category & Frequencies & Percentage \% \\
\hline 13 to 19 years & 40 & 26.84 \\
$\mathbf{2 0}$ to 30 years & 68 & 45.63 \\
$\mathbf{3 1}$ to 34 years & 18 & 12.1 \\
$\mathbf{3 5}$ to 49 years & 22 & 14.76 \\
$\mathbf{5 0}$ & 1 & 0.67 \\
Total & 149 & $100 \%$ \\
\hline
\end{tabular}

\subsection{Employment Status}

The study found that 108 (72.5\%) of the participants were unemployed while $41(27.5 \%)$ were employed.

Table 2. Employment status

\begin{tabular}{lcc}
\hline Employment status & Frequencies & Percentage \% \\
\hline Unemployed & 108 & 72.5 \\
Employed & 41 & 27.5 \\
Total & 149 & $100 \%$ \\
\hline
\end{tabular}

\subsection{Gravidity Before Delivery}

It emerged that $52 \%(n=78)$ were multigravida, $: 44 \%(n=65)$ were primigravida while $4 \%(n=6(4 \%)$ grand multipara (see Table 3 below).

Table 3. Gravidity of participants before delivery

\begin{tabular}{lcc}
\hline Gravidity & Frequencies & Percentage\% \\
\hline Multigravida & 78 & 52 \\
Primigravida & 65 & 44 \\
Grande multipara & 6 & 4.0 \\
Total & 149 & $100 \%$ \\
\hline
\end{tabular}




\subsection{Type of Pregnancy}

Table 4 below indicates the pregnancy type as found in the files, which were reviewed with the majority of the women having a singleton pregnancy $(96.6 \%)$ and few only with multiple pregnancies $(3.36 \%)$.

Table 4. Type of pregnancy

\begin{tabular}{lcc}
\hline Type of pregnancy & Frequency & Percentage \% \\
\hline Singleton pregnancy & 145 & 96 \\
Multiple pregnancy & 6 & 4.0 \\
Total & 149 & 100 \\
\hline
\end{tabular}

\subsection{Antenatal Care Attendance}

The records indicated that 144 (97\%) of the women had attended antenatal care while 5 of the women (3\%) had not attended antenatal care during pregnancy.

Table 5. Antenatal care attendance

\begin{tabular}{lcc}
\hline Antenatal care attendance & Frequency & Percentage \% \\
\hline Attended & 144 & 97 \\
Not attended & 5 & 3 \\
Total & 149 & 100 \\
\hline
\end{tabular}

\subsection{Indications of Caesarean Section}

Table 6 below presents the following indications of $\mathrm{C} / \mathrm{S}$, namely, foetal distress $25.6 \%$, $(\mathrm{n}=38)$ previous $\mathrm{C} / \mathrm{S}$ scar $18.1 \%(\mathrm{n}=27)$ CPD $16.1 \%(\mathrm{n}=24) 16.1 \%$ malpresentation $(\mathrm{n}=10) 6.7 \%, 9.4 \%$, eclampsia/pre-eclampsia $(\mathrm{n}=$ 12) $8.1 \%$. Furthermore, the study findings revealed the following indications of $\mathrm{C} / \mathrm{S}$, namely; ante partum haemorrhage $7.4 \%(n=11)$, prolonged labour $6.7 \%(n=10)$, multiple pregnancy $4.0 \%(n=5)$, failed induction of labour $3.4 \%(n=5), 2.0 \%$ failed vaginal birth after caesarean section $(n=3)$, cord prolapse $1.3 \%(n=2)$ and severe vaginal warts $0.6 \%(\mathrm{n}=1)$.

Table 6. Indications of caesarean section

\begin{tabular}{lcc}
\hline Indications of caesarean section & Frequency & Percentage \% \\
\hline Foetal distress & 38 & 25.6 \\
Previous caesarean section & 27 & 18.1 \\
Cephalopelvic disproportion & 24 & 16.1 \\
Pre-eclampsia/eclampsia & 12 & 8.1 \\
Antepartum haemorrhage & 11 & 7.4 \\
Malpresentation & 10 & 6.7 \\
Prolonged labour & 10 & 6.7 \\
Multiple pregnancies & 6 & 4.0 \\
Failed induction & 5 & 3.4 \\
Failed Vaginal birth after caesarean section & 3 & 2.0 \\
Cord prolapse & 2 & 1.3 \\
Severe vaginal warts & 1 & 0.6 \\
Total & 149 & 100. \\
\hline
\end{tabular}




\section{Discussion}

This study revealed the common age for $\mathrm{C} / \mathrm{S}$ among women was 20 to 30 years old respectively. According to the Namibia Ministry of Health and Social Services (MoHSS) and ICF International (2014), the normal reproductive age is between 20 and 30 years with this age range being considered to have the best delivery outcomes for both mother and foetus. This finding is similar to a study conducted at Al-Wahda hospital, Libya which found out that majority of women undergoing C/S were in the 20 to 30 years' age group (Elzahaf \& Ajroud, 2018). Similar findings were reported in a study conducted in the Punjab Institute of Medical Sciences, which revealed that most of the mothers undergoing $\mathrm{C} / \mathrm{S}$ were between the ages of 21 to 30 years. On the other hand, a study conducted in a rural block of the State of West Bengal found that the common age group of women who delivered by $\mathrm{C} / \mathrm{S}$ had increased to between the ages of 25 and 30 years (Pal, Mondal, \& Ghosh, 2015).

In addition, this study reported high number of women aged 13 and 19 years (adolescents) as having undergone a $\mathrm{C} / \mathrm{S}$. The study finding is supporting the findings of higher rate of adolescent pregnancy in Kavango region, Namibia (The Namibia Ministry of Health and Social Services (MoHSS) and ICF International, 2014). Adolescent pregnancy is defined as pregnancy in a young girl between the age of 13 and19 (Spencer, 2011). According to Nilsen (2014), the high C/S percentages in adolescents could be caused by obstructed labour due to an immature birth canal. This means that they became pregnant before the pelvis had matured, resulting in cephalo-pelvic disproportion which plays a central role in obstructed labour. The results of this study in relation to girls aged 12 to 20 years, in which younger adolescent age was used as an impartial factor for $\mathrm{C} / \mathrm{S}$, revealed that the incidence of $\mathrm{C} / \mathrm{S}$ increases as maternal age decreases (Malabarey, Balayla, \& Abenhaim, 2012).

Although this study's findings relating to the $26.84 \%$ of adolescent girls who had undergone $\mathrm{C} / \mathrm{S}$ was of interest it was, nevertheless, not surprising as Namibia has been cited as one of the countries with the highest adolescent pregnancy rates in Africa (Ministry of Education, Arts and Culture [MOE], 2010). Overall, the study's findings were in line with the findings of a previous study on the teenage pregnancy rate which was conducted in the Kavango region by the United States Agency for International Development (USAID) (2011), which stated that the teenage pregnancy rate in the Kavango region was double the national average at $34 \%$ for the 15 to 19 years' old age group. It may, therefore, be suggested that operational measures in relation to avoiding adolescent pregnancy should be improved and reinforced at schools from an early age. Health education and sex education should be introduced as a school subject and teachers instructing adolescents on the disadvantages or danger of failing pregnant at a young age. In addition, a friendly policy in respect of family planning that allows adolescents to gain access to free contraceptives without fear of discrimination and/or intimidation should be implemented.

This study also revealed that $12.1 \%$ of the women who underwent $\mathrm{C} / \mathrm{S}$ were in the age group 31 to 34 years. This result is contrary to the findings of a study conducted by Rydal et al., (2019) which reported that $25 \%$ of women who underwent $\mathrm{C} / \mathrm{S}$ were between 30 and 34 years. The findings of this study are similar to those of the study conducted by Janoudi et al. (2015) who discovered that women aged 35 or older experienced a greater number of obstetrical complications as compared to women aged between 20 and 34 with such complications putting them at risk of C/S. The findings of this study also concur with the study done by Nilsen (2014) which found that $\mathrm{C} / \mathrm{S}$ in higher maternal age groups was associated with medical conditions such as hypertension and diabetes. Moreover, in the industrialised world, social, demographic and educational social trends combined with the greater accessibility of birth control and wider solutions to infertility problems has increased the proportion of women experiencing their first pregnancy after the age of 35 (Cohen, 2014). However, Mylonas and Friese (2015) emphasised that age is not, in itself, an indication for $\mathrm{C} / \mathrm{S}$ but, rather, it is the occurrence of specific risks in this group that may result in indications for $\mathrm{C} / \mathrm{S}$, for example, woman may have hypertension which may be an indication for $\mathrm{C} / \mathrm{S}$.

Of the total population more, than half of the files reviewed indicated that the majority of the woman were unemployed, thus indicating a poor socio-economic status. Rundu is a semi-rural area and the majority of the inhabitants survive on subsistence farming. This could also contribute to the high rate of unemployment rate among the community members. This study's findings were in line with those of a study conducted by Shamshad (2008) in Pakistan which identified that the majority of women who had undergone $\mathrm{C} / \mathrm{S}$ were unemployed and of a poor socio-economic status.

In their study carried out in 2017 Patil et al found that, in relation to an emergency $\mathrm{C} / \mathrm{S}$, multiple pregnancies contributed to $2.9 \%$ - lower than the $4.0 \%$ reported in this study. This study also revealed a higher rate of $\mathrm{C} / \mathrm{S}$ was among primigravida. The high number of women undergoing $\mathrm{C} / \mathrm{S}$ for the first time is an issue of great concern in light of the implications for future pregnancies and deliveries. In addition, the high number of $\mathrm{C} / \mathrm{S}$ cases in primigravida will also result in an increase in the number of women with previous $\mathrm{C} / \mathrm{S}$ in the future and, therefore, 
it is clearly important to prevent the first $\mathrm{C} / \mathrm{S}$ where possible. This study reported a high rate $44 \%$ of primigravida who had undergone $\mathrm{C} / \mathrm{S}$ as opposed to the $23.2 \%$ of primigravida who had undergone $\mathrm{C} / \mathrm{S}$ as reported to a study conducted in the Military Hospital Rawalpindi (Saijad, 2014).

The majority of the women whose files were reviewed in this study had attended ANC with only a few not attending ANC. In Namibia, a national policy of free maternal and child (less than 5 years) health care at public health facilities was implemented in 2000 in order to improve the accessibility and availability of maternal and child services throughout the country (MoHSS, 2010).In addition, antenatal care service is rendered free of charge in all public health facilities. This has resulted in the increased use of health services for both ANC and delivery services in the country. Namibia has managed to attain a 95\% ANC coverage which is above the authorised target (MoHSS, 2010). More than $80 \%$ of all deliveries occur in public institutions while $81.4 \%$ of all deliveries are carried out by skilled birth attendants. These statistics may be the reason for high rate of C/S (MOHSS, 2010). The findings of this study are in line with the findings of studies conducted by Witter and Diadhiou (2008) and Witter et al. (2010) in Hajjah hospital and Yemen hospital. The fact that both of these hospitals offer free antenatal care and free $\mathrm{C} / \mathrm{Ss}$ may be one of the reasons for the high incidence of caesarean deliveries. The policy of free caesarean deliveries, which was recommended and adopted by many countries, in a bid to improve access to emergency obstetric care has been found to increase the incidence of caesarean deliveries (Witteret al., 2010).

The indications for $\mathrm{C} / \mathrm{S}$ are divided into two categories, namely, foetal and maternal conditions. This study found that foetal conditions constituted $39 \%$ of $\mathrm{C} / \mathrm{S}$. The most common of such foetal conditions was foetal distress at $25.50 \%$. However, this finding was lower than the $50 \%$ reported in a study conducted in the Kamineni Institute of Medical Sciences (Balmur \& Guthi, 2017) but higher than the $10.0 \%$ recently reported in an audit of C/S carried out in Pakistan (Sajjad et al., 2014). These variations may be attributed to the various methods used to detect foetal distress and the samples of the populations under investigation. In the hospital were the study is conducted the most common method employed for monitoring foetal heart rate (FHR) in labour is the cardiotocography (CTG). Nevertheless, despite the fact that there are guidelines on the diagnosis of foetal distress, in practice what constitutes foetal distress may differ from one clinician to another based on inter and intra-observer differences in the interpretation of foetal heart rate patterns. In the Rundu State Hospital, foetal distress is diagnosed based on an abnormal foetal heart rate as indicated on the CTG and /or meconium stained liquor. Ideally, CTG shows the foetal heart rate response both to foetal movement and maternal contractions. The trace it produces may be interpreted as reassuring, non-reassuring or abnormal. In Rundu State Hospital, the CTG was of poor quality, as most of CTGs did not have tocographic (uterine contractions) recordings as the midwives used one probe only to listen to the FHR without printing it. This may be due to a lack of equipment, proper facilities and skilled workers who are trained in CTG interpretation. The practice of not using both probes to print the CTG may mean foetal asphyxia will not be detected early enough, thus resulting in a poor outcome. Nonetheless, when the CTG is used to listen for the foetal heart for a few minutes only this may result in incorrectly diagnosed foetal asphyxia that lead to an unnecessary C/S. Ideally, the suspicion of foetal distress should be also confirmed by both foetal scalp blood sampling for $\mathrm{pH}$ and lactate determination (Inyanga-Otu, 2014). There are appropriate methods that are easy to use when monitoring foetal heart rate in low risk labour, for example, intermittent auscultation with fetoscope and doptone. When such methods are not used, this may lead to an incorrect diagnosis, which may then result in an unnecessary C/S (Inyanga-Otu, 2014).

Cephalo-pelvic disproportion constituted $16 \%$ of $\mathrm{C} / \mathrm{S}$ in this study. This represented the only subjective assessment made by the attending healthcare providers based on a pelvic assessment and based primarily on findings during labour. Overall, the findings of this study contradicted the findings in previous studies conducted in other countries that used a different terminology such as arrest of dilatation, arrest of descent and dystocia. It is possible such diagnoses may have been recorded in the patient records as poor progress (Inyang-Otu, 2014; Barber et al., 2011). The findings of this study suggest a degree of subjectivity in clinical assessment an adjustable factor which, if addressed, might lead to fewer instances of $\mathrm{C} / \mathrm{S}$.

The current study also reported a higher rate of $81.9 \%$ primary $\mathrm{C} / \mathrm{S}$ as compared to the $68.7 \%$ and $67.6 \%$ reported on other studies (Chukwu et al., 2017; Geidam et al., 2009). Mothers who had a primary C/S are more likely to have a $\mathrm{C} / \mathrm{S}$ delivery in future pregnancies as health workers are reluctant to try a vaginal delivery in the case of women with a $\mathrm{C} / \mathrm{S}$ scar. This may be due to the fear of litigation as a result of uterine rupture and the associated risk to both the mother and the foetus. It is, therefore, clear that primary $\mathrm{C} / \mathrm{S}$ should be avoided whenever possible.

The findings of this study revealed that mothers with previous $\mathrm{C} / \mathrm{S}$ were more prone to have a subsequent $\mathrm{C} / \mathrm{S}$ as compared to their counterparts with no history of $\mathrm{C} / \mathrm{S}$. These findings are similar to those of the study conducted by Shamshad, (2008) that found that repeated C/S was the most common indication for $\mathrm{C} / \mathrm{S}$. The guideline established 
that women with previous $\mathrm{C} / \mathrm{S}$ should be given information during their antenatal visits to enable them to give their informed consent as to whether they wished to attempt a VBAC or proceed directly to C/S. Those women who agreed to VBAC would be admitted at 38 weeks of gestation to wait for spontaneous labour while those who did not agree should be booked for a C/S at about 38 weeks (MoHSS, 2009). It is, thus, recommended that the existing rules in Namibia for the management of patients with a previous $\mathrm{C} / \mathrm{S}$ be changed and that the patient be evaluated at approximately 36 weeks of gestation and decision made on the mode of delivery.

According to Lavender et al. (2012), C/S may possibly reduce the incidence of litigations associated with vaginal deliveries. Furthermore, Nyamtema et al.(2008) also support the view that fear of litigation also affects the attitude of many doctors who tend to perform C/Ss. However, Abebe et al., (2016) discovered that trial of scar in singleton pregnancies could be carried out to reduce the rate of repeated $\mathrm{C} / \mathrm{Ss}$ as the risk of uterine rupture is low in singleton pregnancies compared to multiple pregnancies.

Pregnancy inductive hypertension (PIH) that developed into pre-eclampsia and then eclampsia contributed to the statistic of $8.05 \%$ in respect of women who underwent an emergency $\mathrm{C} / \mathrm{S}$. The possible interpretation of pre-eclampsia and eclampsia may arise from the fact that the Rundu State Hospital is a referral hospital with the possibility of a number of the patients being referred from peripheral hospitals and who may have received suboptimal care prior to their being referred. This study reported an $8.05 \%$ hypertensive disorder of pregnancy with lower than the $27.1 \%$ reported in a study conducted by Al-Rukeimi, Al-Haddad \& Adam, (2013) on the overuse of caesarean delivery at the Al-Saudi Hospital in Hajjah, Yemen. The discrepancy between the findings may stem from the fact that the study in Yemen was a large study using a big sample and conducted over a period of one year while this study was a small study with small sample and conducted over a period of 3 months.

\subsection{Limitations of the Study}

One of the limitations of the study was the retrospective design used and because of which the validity of the study applied only to the population under study. In addition, the fact that the Rundu State Hospital, the setting of the study, serves as a referral centre may mean that the findings of the study are not necessarily generalisable to non-referral hospitals.

\section{Conclusion}

In conclusion, the study found that the age of the participants ranged between 13 and 50 years with the majority of the participants being in the age group of 20 to 30 years with a mean age of 25.1 years. The majority of the participants had a singleton pregnancy and only a few had multiple pregnancies. In addition, the study found out that a primary $\mathrm{C} / \mathrm{S}$ was more common than previous uterine scar. Overall, the study found that the leading indications for $\mathrm{C} / \mathrm{S}$ included foetal distress, previous uterine scar and cephalopelvic disproportion. However, it is recommended that foetal distress, as the main indication for a primary $\mathrm{C} / \mathrm{S}$, should be further confirmed with a printed cardiotocograph. The training of health workers on the interpretation of cardio-tocographs and the importance of using other methods such as the fetoscope and doptone to monitor foetal heart rate may help to reduce the use of primary $\mathrm{C} / \mathrm{S}$ as a result of foetal distress. In addition, the increase in $\mathrm{C} / \mathrm{S}$ due to previous single caesarean section could be decreased by allowing the mother to undergo a trial labour for vaginal delivery.

\section{Competing Interests Statement}

The authors declare that there are no competing or potential conflicts of interest.

\section{References}

Abebe, F. E., Gebeyehu, W. A., Kidane, N. A., \& Ayassu, A. G. (2016). Factors leading tosection delivery at Felegehiwot referral hospital. Reproductive, 13(6), 35-43. https://doi.org/10.1186/s12978-015-0114-8

Al-Rukeimi, A. A., Al-Haddad, A., \& Adam, I. (2013). Overuse of cesarean delivery at Al-Saudi Hospital, Hajjah, $\begin{array}{lllll}\text { Yemen. Sudan Journal of Medical } & \text { Sciences, } & 8(4), & \text { 185-188. }\end{array}$ https://www.ajol.info/index.php/sjms/article/viewFile/104456/94536

Barber, E. L., Lundsberg, L. S., Belanger, K., Pettker, C. M., Funai, E. F., \& Illuzzi, J. L. (2011). Indications contributing to the increasing cesarean delivery rate. Obstet Gynecol, 118(1), 29-38. https://doi.org/10.1097/AOG.0b013e31821e5f65

Balmur, S. K., Guthi, V. R., \& Naidu, N. K. (2017). Analysis of delivery pattern and neonatal outcome in the calendar year 2015 in urban field practice area of Kamineni Institute of Medical Sciences, Narketpally, India. International Journal of Reproduction, Contraception, Obstetrics and Gynecology, 6(2), 592. https://doi.org/10.18203/2320-1770.ijrcog20170388 
Betran, A. P., Merialdi, M., Lauer, J. A., Bing-Shun, W., Thomas, J., Look, P. V., \& Wagner, M. (2007). Rates of caesarean section: Analysis of global, regional and national estimates.Paediatric, Perinal. Epidemiology, 21, 98-113. https://doi.org/10.1111/j.1365-3016.2007.00786.x

Cohen, W. R. (2014). Does maternal age affect pregnancy outcome? BJOG: An International Journal of Obstetrics \& Gynaecology, 121(3), 252-254. https://doi.org/10.1111/1471-0528.12563

Chukwu, E. O., Ekeh, C. J., Haruna, H., Chia, T., \& Fiase, T. M. (2017). Prevalence of caesarean section deliveries among primigravidae in general hospital Gboko, Benue state, Nigeria. International Journal of Clinical and Experimental Medical Sciences, 3(5), 61. https://doi.org/10.11648/j.ijcems.20170305.12

Elzahaf, R. A., \& Ajroud, S. (2018). Prevalence and indication of cesarean section in Al-Wahda Hospital, Derna, Libya: A retrospective study. Libyan Journal of Medical Sciences, 2(2), 68. https://doi.org/10.4103/LJMS.LJMS_7_18

Inyang-Otu, U. S. (2014). Factors associated with high caesarean section rates in Bertha Gxowa Hospital (Doctoral dissertation). Retrieved from http://hdl.handle.net/10539/15294n

Geidam, A. D., Audu, B. M., Kawuwa, B. M., \& Obed, J. Y. (2009). Rising trend and indications of caesarean section at the university of Maiduguri teaching hospital, Nigeria. Annals of African Medicine, 8(2). https://doi.org/10.4103/1596-3519.56242

Janoudi, G., Kelly, S., Yasseen, A., Hamam, H., Moretti, F., \& Walker, M. (2015). Factors associated with increased rates of caesarean section in women of advanced maternal age. Journal of Obstetrics and Gynaecology Canada, 37(6), 517-526. https://doi.org/10.1016/S1701-2163(15)30228-0

Kirchengast, S., \& Hartmann, B. (2019). Recent lifestyle parameters are associated with increasing caesarean section rates among singleton term births in Austria. International Journal of Environmental Research and Public Health, 16(1). https://doi.org/10.3390/ijerph16010014

Lavender., Hofmeyr, G. J., Nielson, J. P., Kingdon, C., \& Gyte, G. M. (2012). Caesarean section for non-medical reasons at term. The Cochrane database of Systemic Reviews, 3(3). https://doi.org/10.1002/14651858.CD004660.pub3

Malabarey, O. T., Balayla, J., \& Abenhaim, H. A. (2012). The effect of pelvic size on cesarean delivery rates: Using adolescent maternal age as an unbiased proxy for pelvic size. Journal of Paediatric and Adolescent Gynaecology, 25(3), 190-194. https://doi.org/10.1016/j.jpag.2012.01.002

Ministry of Education, Arts and Culture. (2010). Education and Training Sector Improvement Programme Review Report. Windhoek, Namibia: Ministry of Education, Arts and Culture.

Ministry of Health and Social Services. (2010). Roadmap accelerating the reduction of maternal and neonatal morbidity and mortality. Windhoek. Namibia: Ministry of Health and Social Services.

Ministry of Health and Social Services. (2009). Guidelines on Essential and Emergency Obstetric Care. Windhoek. Ministry of Health and Social Services.

Moges, A., Ademe, B. W., \& Gerome Muleta Akessa, G. M. (2015). Prevalence and outcome of caesarean section inAttatHospital, Gurage Zone, SNNPR, Ethiopia. iMedPub Journals, 4(7), 8. Retrieved from http://www.archivesofmedicine.com/

Makori, A. A. A. (2015). The effect of time of day of unscheduled caesarean sections on perinatal and maternal outcomes in Kenyatta national hospital, Nairobi, Kenya (Doctoral dissertation, University of Nairobi).

Molina, G., Weiser, T. G., Lipsitz, S. R., Esquivel, M. M., Uribe-Leitz, T., Azad, T., \& Haynes, A. B. (2015). Relationship between cesarean delivery rate and maternal and neonatal mortality. Jama,314(21), 2263-2270. https://doi.org/10.1001/jama.2015.15553

Mylonas, I., \& Friese, K. (2015). Indications for and risks of elective cesarean section. DeutschesÄrzteblatt International, 112(29-30), 489. https://doi.org/10.3238/arztebl.2015.0489

Namibia Statistic Agency. (2012). Namibia 2011 Population and Housing Census Main Report. Windhoek: Government printers.

The Namibia Ministry of Health and Social Services (MoHSS) and ICF International. (2014). The Namibia Demographic and Health Survey 2013. Windhoek, Namibia, and Rockville, Maryland, USA: MoHSS and ICF International.

Nilsen, C. (2014). Trends in and socio-demographic factors associated with caesarean section at a large 
Tanzanian hospital(Master of Philosophy in International Health). Centre for International Health Faculty of Medicine and Dentistry University of Bergen, Norway. https://doi.org/10.1186/s12939-014-0087-1

Nyamtema, A., Urassa, D., Massawe, S., Massawe, A., Lindmark, G., \& Van Roosmalen, J. (2008). Partogram use in the Dar es Salaam perinatal care study. International Journal of Gynecology\& Obstetrics, 100(1), 37-40. https://doi.org/10.1016/j.ijgo.2007.06.049

Patil, P., Bhardwaj, M., Sharma, P., \& Chandrakar, G. (2017). Changing trends in indication of cesarean section in a tertiary care centre of Central India. Int J Reprod Contracept Obstet Gynecol., 6(7), 2829-2835. https://doi.org/10.18203/2320-1770.ijrcog20172561

Patah, L. E., \& Malik. A. M. (2011). Models of childbirth care and cesarean rates in different countries. Rev Saude Publica, 45, 185-94. http://dx.doi.org/10.1590/S0034-89102011000100021

Pal, D. K., Mondal, T., \& Ghosh, R. (2015). Epidemiological determinants affecting caesarean section in a rural block of West Bengal. IOSR J Dent Med Sci., 14, 120-2. http://dx.doi.org/10.9790/0853-14118120122

Pallasmaa, N., Ekblad, U., Aitokallio-Tallberg, A., Uotila, J., Raudaskoski, T., Ulander, V. M., \& Hurme, S. (2010). Cesarean delivery in Finland: Maternal complications and obstetric risk factors. Acta Obstetriciaet Gynecologica Scandinavica, 89(7). https://doi.org/10.3109/00016349.2010.487893

Rydahl, E., Declercq, E., Juhl, M., \& Maimburg, R. D. (2019). Cesarean section on a rise: Does advanced maternal age explain the increase? A population register-based study. PloS One, 14(1). https://doi.org/10.1371/journal.pone.0210655

Sajjad, R., Ali, C. A., Zia-ul-Haq, M., \& Iqbal, A. (2014). An audit of cesarean sections in Military Hospital Rawalpindi. Anaesthesia, Pain \& Intensive Care, 172-175. Retrieved from http://www.apicareonline.com/wordpress/wp-content/uploads/2014/12/09-Pages-172-175.pdf

Shamshad, B. (2008). Factors leading to increased cesarean section rate. Gomal J Med Sci, 6(1), 1-5.

Shikwambi, H. (2014). Non-elective caesarean section in the Khomasregion, Namibia: Implications for midwifery practice. Retrieved from http://hdl.handle.net/11427/13315

Spencer, S. (2011). Thehow: Facts about teenage pregnancy.Journal for Studies in Humanities. Retrieved fromhttp://www.ehow.com/about_4619346_teen

United States Agency for International Development (USAID). (2011). Teenage Pregnancy in Kavango Region: Contributing Factors and Program Recommendation.

Witter, S., \& Diadhiou, M. (2008). Key informant views of a free delivery and cesarean policy in Senegal. Afr $J$ Reprod Health, 12(3), 93-111.

Witter, S., Dieng, T., Mbengue, D., Moreira, I., \& De Brouwere, V. (2010). The national free delivery and cesarean policy in Senegal: Evaluating process and outcomes. Health Policy Plan, 25(5), 384-392. https://doi.org/10.1093/heapol/czq013

World Health Organization [WHO]. (2009). Maternal and Child Health in Namibia (2nd ed.). Retrieved from www.who.int/.../maternal/mch_namibia.pdf

World Health Organization [WHO]. (2015). Warnsofcaesareanepidemic. Retrieved from https://www.bmj.com/content/363/bmj.k4319.full

World Health Statistics. (2012). Part III. Global Health Indicators. Retrieved from http://www.who.int/gho/publications/worldhealthstatistics/2012/en/

Xu, X., Lee, H. C., Lin, H., Lundsberg, L. S., Campbell, K. H., Lipkind, H. S., ... \& Illuzzi, J. L. (2019). Hospital variation in utilization and success of trial of labor after a prior cesarean. American Journal of Obstetrics and Gynaecology, 220(1), 98-e1. https://doi.org/10.1016/j.ajog.2018.09.034

\section{Copyrights}

Copyright for this article is retained by the author(s), with first publication rights granted to the journal.

This is an open-access article distributed under the terms and conditions of the Creative Commons Attribution license (http://creativecommons.org/licenses/by/4.0/). 